\title{
Understanding the Game Theory of the Prisoner's Dilemma
}

\author{
Meri Algarni \\ Faculty Member in the \\ Department of Physics \\ at Al-Baha University, \\ Al-Baha, Saudi Arabia. \\ Department of Physics at \\ Clark Atlanta University, \\ GA,30314, USA.
}

\begin{abstract}
The prisoner dilemma (PD) is the best-known session of procedure in sociology. It helps us comprehend what oversees the harmony amongst collaboration and rivalry in business, in governmental issues, and in social settings. Diversion hypothesis is regularly presented in college classes with regards to a detainee's difficulty worldview, which shows the contention between motivating social forces to collaborate and private impetuses to abscond. This paper exhibits an extremely straightforward card amusement that effectively includes an extensive number of understudies in a Prisoner's Dilemma. The degree of participation is influenced by the result impetuses and by way of rehashed connection.
\end{abstract}

\section{General Terms}

Prisoner's Dilemma.

\section{Keywords}

Prisoner's Dilemma, game theory and quantum game.

\section{INTRODUCTION}

Prisoner's Dilemma (PD), which is a game of two prisoners who have allegedly committed a crime together. They are being interrogated in separate cells. Each of the prisoners has to decide either to admit the crime to defect (D) or to refuse the crime to cooperate (C) without any communication between them. The prisoner's dilemma itself is well established as a way to study the emergence of cooperative behavior. Every player is simultaneously offered two options: to cooperate (C) or defect (D). If both players cooperate, they each receive the same payoff; if both defect, they each receive a lower payoff; if one player cooperates and the other defects, the defector receives the largest possible payoff, and the cooperator the lowest possible payoff. It is difficult that a unilateral participant tries to find a simple optimal strategy.

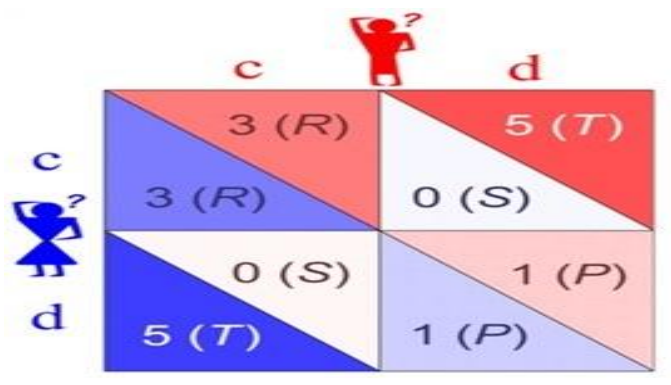

Within the event that both coordinate, each will accumulate a prize $(\mathrm{R})$, On the off threat that one imperfection and alternate coordinates, the defector will get a greater allurement influence (T) while the cooperator will get a little sucker's outcomes (S). On the off chance that each deformity, every will pick up a discipline influence $(\mathrm{P})$. The estimations of $\mathrm{R}$, $\mathrm{T}, \mathrm{S}$ and $\mathrm{P}$ have got to fulfill two stipulations:

$$
\mathrm{T}>\mathrm{R}>\mathrm{P}>\mathrm{S} \text { moreover, } 2 \mathrm{R}>\mathrm{T}+\mathrm{S}
$$

So, The conventional values $(\mathrm{T}, \mathrm{R}, \mathrm{P}, \mathrm{S})=(5,3,1,0)$

$$
\begin{aligned}
& \mathrm{T}>\mathrm{R}>\mathrm{P}>\mathrm{S} \longrightarrow 5>3>1>0 \\
& 2 \mathrm{R}>\mathrm{T}+\mathrm{S} \quad \longrightarrow 6>5
\end{aligned}
$$

\section{ELABORATING THE IDEAS OF PD}

The following five points are required to elaborate the ideas of PD

1. The con artist's reward comes without a moment's delay, while the misfortune from discipline lies later on. On the off chance that players vigorously rebate future adjustments, then the misfortune might be inadequate to hinder conning. Subsequently, participation is harder to maintain among exceptionally restless players (governments, for instance).

2. Discipline won't work unless tracking can be recognized and rebuffed. In this manner, organizations collaborate progressively when their activities are all the more effortlessly distinguished (setting costs, for instance) and less when activities are less effectively recognized (settling on nonprime characteristics of products, for example, repair guarantees). Discipline is simpler to mastermind in littler and shut gatherings. Along these lines, enterprises with few firms and less danger of new passage will probably be conniving.

3. Discipline can be made programmed by taking after systems like "blow for blow." This thought was promoted by University of Michigan political researcher Robert Axelrod. Here, you cheat if and just if your adversary deceived in the past round. In any case, if adversaries' simple activities can be misjudged as bamboozling, then one good turn deserves another risk setting off progressive rounds of baseless countering.

4. A settled, limited number of reiterations is coherently insufficient to yield collaboration. Both or all players realize that dumping is the useful technique in the last play. Given this, the same goes for the second-last play, then the third 
keep going, et cetera. In any case, by and by we see some participation in the early adjusts of a settled arrangement of redundancies. The reason might be either that players don't have the foggiest idea about the quantity of rounds without a doubt, or that they can misuse the likelihood of "nonsensical excellence" further bolstering their common good fortune.

5. Participation can likewise emerge if the gathering has an extensive pioneer, who by and by stands to lose a great deal from through and through rivalry and in this manner practices limitation, despite the fact that he realizes that other little player will swindle. Saudi Arabia's part of "swing maker" in the OPEC cartel is an example of this.

\section{THE HOSTRY OF THE PD}

The Prisoner's Dilemma is a standard case of an amusement examined in diversion hypothesis that shows why two totally "discerning" people won't collaborate, regardless of the possibility that it gives the idea that it is to their greatest benefit to doing as such. It was initially surrounded by Merrill Flood and Melvin Dresher working at RAND in 1950. Albert W. Tucker formalized the diversion with jail sentence remunerates and named it, "detainee's issue" (Pound stone, 1992), showing it as takes after:

Two individuals from a criminal group are captured and detained. Every detainee is in isolation without any method for speaking with the other. The prosecutors need adequate proof to convict the match on the chief charge. They want to get both sentenced to a year in jail on a lesser accusation. At the same time, the prosecutors offer every detainee a deal. Every detainee is given the open door either to: deceive the other by affirming that the other carried out the wrongdoing, or to coordinate with the other by staying quiet. The proposal are following: In the event that A and B sell out the other, Each of them serves two years in jail On the off chance that A receives B. Nonetheless, B stays noiseless, A will be without set and B will serve 3 years in jail (and the other way around) On the off chance that An and B both stay noiseless, the two will just serve 1 year in jail (on the lesser accusation). It is suggested that the detainees will have no chance to compensate or rebuff their accomplice other than the jail sentences they get and that their choice won't influence their notoriety later on. Since selling out an accomplice offers a more prominent reward than participating with him, all reasonable self-intrigued detainees would double-cross the other. Thus the main conceivable result for two simple objective detainees is for them to deceive each other.[1] The fascinating a portion of this outcome is that seeking after individual reward consistently drives both of the detainees to double-cross when they would show signs of improvement reward on the off chance that they both kept noiselessly. In all actuality, people show a systemic inclination towards helpful conduct in this and comparative diversions, a great deal more so than anticipated by straightforward models of "reasonable" self-intrigued action [2][3][4][5]. A model in view of an alternate sort of objectivity, where individuals conjecture how the amusement would be played in the event that they framed coalitions, and afterward they boost their gauges, has been appeared to inhance expectations of the rate of participation in this and comparable recreations gave just the settlements of the game [6]. An expanded "iterated" form of the diversion additionally exists, where the great amusement is played over and again between similar detainees, and therefore, both detainees persistently have a chance to punish the other for past choices. On the off chance that the quantity of times the diversion will be played is known to the players, then (by in reverse acceptance) two traditionally balanced players will deceive each other more than once, for an indistinguishable reason from the single-shot variation. In a large or obscure length amusement, there is no settled ideal system, and Prisoner's Dilemma competitions have been held to contend and test algorithms [7].The detainee's problem amusement can be utilized as a model for some certifiable circumstances including agreeable conduct. In easygoing use, the mark "detainee's difficulty" might be connected to circumstances not entirely coordinating the formal criteria of the work of art or iterative amusements. For example, those in which two substances could increase significant advantages from collaborating or experience the ill effects of the inability to do as such, however, discover it only troublesome or costly, not incomprehensible, to arrange their exercises to accomplish participation.

\section{ZERO DETERMNIAT (ZD) STRATEGY}

There is various outcome recognized with this game. Right, here we have a type of system, called zero-determinant strategies.

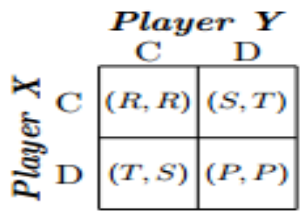

Player's $\mathrm{X}$ and $\mathrm{Y}$ have the same memory.

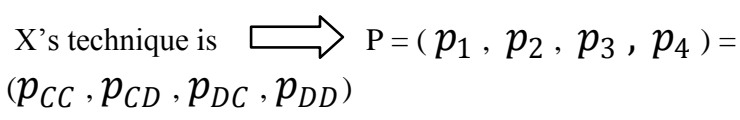

Y's technique is $\Longrightarrow \mathrm{q}=\left(q_{1}, q_{2}, q_{3}, q_{4}\right)=$ $\left(q_{C C}, q_{C D}, q_{D C}, q_{D D}\right)$

There are four possible outcomes $\mathrm{XY} \in(\mathrm{CC}, \mathrm{CD}, \mathrm{DC}, \mathrm{DD}) \quad \square$

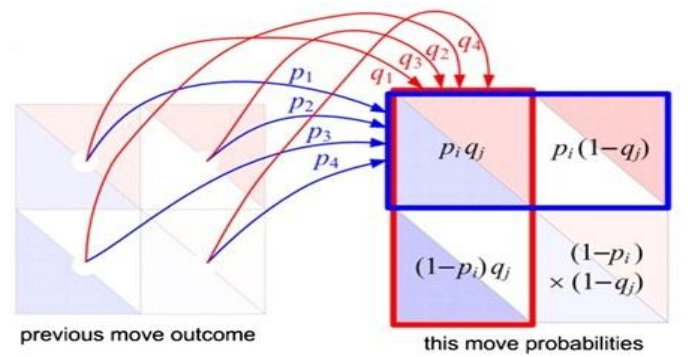


The continuous outcomes follow a Markov Chain.

Then, we can get sixteen transition probabilities indicated by $\mathrm{M}(\mathrm{p}, \mathrm{q})$.

$$
\mathrm{M}(\mathrm{p}, \mathrm{q})=\left(\begin{array}{llll}
p_{1} q_{1} & p_{1}\left(1-q_{1}\right) & \left(1-p_{1}\right) q_{1} & \left(1-p_{1}\right)\left(1-q_{1}\right) \\
p_{2} q_{3} & p_{2}\left(1-q_{3}\right) & \left(1-p_{2}\right) q_{3} & \left(1-p_{2}\right)\left(1-q_{3}\right) \\
p_{3} q_{2} & p_{3}\left(1-q_{2}\right) & \left(1-p_{3}\right) q_{2} & \left(1-p_{3}\right)\left(1-q_{2}\right) \\
p_{4} q_{4} & p_{4}\left(1-q_{4}\right) & \left(1-p_{4}\right) q_{4} & \left(1-p_{4}\right)\left(1-q_{4}\right)
\end{array}\right)
$$

$\mathrm{X}$ cooperates when the outcome is $\mathrm{CC}, \mathrm{CD}, \mathrm{DC}, \mathrm{DD}$.
$\mathrm{Y}$ cooperates

So,

sixteen transition probabilities $\square \mathrm{XY} \in(\mathrm{CC}, \mathrm{CD}, \mathrm{DC}, \mathrm{DD})$

However, $p_{2}$ and $q_{2}$ have different outcomes: if we switch the letters of an outcome and let the first letter be the choice of $\mathrm{Y}$, then $\mathrm{q}$ represents the probabilities that $\mathrm{Y}$ cooperates

$$
\begin{aligned}
& \text { 1-P }(C C \mid C C)=p_{1} q_{1} \\
& \text { 2-P }(C D \mid C C)=p_{1}\left(1-q_{1}\right) \\
& \text { 3-P }(D C \mid C C)=\left(1-p_{1}\right) q_{1} \\
& \text { 4-P }(D D \mid C C)=\left(1-p_{1}\right)\left(1-q_{1}\right) \\
& \text { 5-P }(C C \mid C D)=p_{2} q_{3} \\
& \text { 6-P }(C D \mid C D)=p_{2}\left(1-q_{3}\right) \\
& \text { 7-P (DC } \mid C D)=\left(1-p_{2}\right) q_{3} \\
& \text { 8-P (DD } \mid C D)=\left(1-p_{2}\right)\left(1-q_{3}\right)
\end{aligned}
$$

\section{EXAMINING THE PRISONER'S DILEMMA}

While the Prisoner's Dilemma is a very referred to a case in universal relations hypothesis, it is additionally essential to analyze whether the results would emerge in the physical world. Again, sanely, ever player ought to surrender keeping in mind the end goal to get their best result. In any case, different components may drive them to collaborate, even in a one-time emphasis of the diversion. For example, two researchers at the University of Hamburg chose to test the Prisoner's Dilemma on understudy subjects, and additionally on detainees. The trial varied from the cases of the detainee's problem in writing, where, rather than jail sentences, the subjects are given prizes, either cash (for the understudies), or cigarettes and espresso (Nisen, 2013). Given what normal decision says in regards to inspirations, it was excepted that many would desert. What they found was intriguing: "just $37 \%$ of understudies participated. Prisoners collaborated 56\% of the time. On a couple of premises, just $13 \%$ of understudy sets figured out how to get the best-shared result and coordinate, while $30 \%$ of detainees do. In the successive diversion, significantly more understudies (63\%) participate, so the common collaboration rate. It is fascinating to consider the reasons that these results may have been identified with. From one perspective, it is conceivable that individuals are not all that doubting of others. Be that as it could, the result of this present detainee's situation trial could likewise be on account of the stakes were not as high, or given different inspirations not caught in the review.

\section{REAL EXAMPLES OF PD}

The detainee setting may appear to be thought up, yet there are in certainty numerous cases in human association and when the previous outcome is $\mathrm{CC}, \mathrm{CD}, \mathrm{DC}$, and $\mathrm{DD}$.

So, sixteen transition probabilities

$\in(C C, C D, D C, D D)$

$$
\begin{aligned}
& \text { 9- } P(C C \mid D C)=p_{3} q_{2} \\
& 10-P(C D \mid C C)=p_{3}\left(1-q_{2}\right) \\
& 11-P(D C \mid D C)=\left(1-p_{3}\right) q_{2} \\
& 12-P(D D \mid D C)=\left(1-p_{3}\right)\left(1-q_{2}\right) \\
& 13-P(C C \mid D D)=p_{4} q_{4} \\
& 14-P(C D \mid D D)=p_{4}\left(1-q_{4}\right) \\
& 15-P(D C \mid D D)=\left(1-p_{4}\right) q_{4} \\
& 16-P(D D \mid D D)=\left(1-p_{4}\right)\left(1-q_{4}\right)
\end{aligned}
$$

additionally collaborations in nature that have a similar result network. The detainee's quandary is consequently important to the sociologies, for example, financial aspects, legislative issues, and human science, and in addition to the organic sciences, for example, ethology and transformative science. Numerous regular procedures have been disconnected into models in which living creatures are occupied with unlimited diversions of detainee's issue. This broad relevance of the PD gives the amusement its generous significance.

\subsection{An Environmental Study}

In natural reviews, the PD is clear in emergencies, for example, global environmental change. It is contended all nations will profit by a steady atmosphere, yet any single nation is frequently reluctant to control $\mathrm{CO} 2$ emanations. The immediate advantage to an individual nation to keep up current conduct is seen to be more prominent than the implied possible advantage to all nations if conduct was changed, in this way clarifying the impasse concerning an environmental change in 2007[8]. An important contrast between environmental change political issues and the detainee's issue is vulnerability; the degree and pace at which contamination can change atmosphere is not known. The predicament confronted by the government is consequently unique about the detainee's situation in that the settlements of participation are obscure. This distinction recommends that states will participate a great deal not exactly in a certain iterated detainee's problem so that the likelihood of staying away from a conceivable atmosphere disaster is much littler than that proposed by a possible diversion investigation of the circumstance utilizing a genuine iterated detainee's dilemma [9]. Osang and Nandy give a hypothetical clarification proofs for a control driven win-win circumstance along the lines of 
Michael Porter's theory, in which government direction of contending firms is substantial [10].

\subsection{In Animal}

Agreeable conduct of many creatures can be comprehended for instance of the detainee's quandary. Regularly creatures participate in long haul associations, which can be all the more particularly demonstrated as iterated prisoner's situation. For instance, guppies assess predators helpfully in gatherings, and they are thought to rebuff non-agreeable examiners. Vampire bats are social creatures that take part in equal nourishment trade. Applying the settlements from the detainee's difficulty can clarify this behavior [11].

C/C "Remunerate: I get blood on my unfortunate evenings, which spares me from starving. I need to give blood on my fortunate nights, which doesn't cost me excessively."

D/C: "Enticement: You spare my life on my poor night. However, then I get the additional advantage of not paying the slight cost of encouraging you on my goodbye.

" C/D: "Sucker's Payoff: I afford the cost of sparing your life on my goodbye. In any case, on my terrible night, you don't nourish me, and I run a genuine danger of starving to death."

D/D: "Discipline: I don't need to pay the slight expenses of sustaining you on my great evenings. In any case, I run a genuine danger of starving on my poor evenings."

\subsection{In Syphcology}

In enslavement inquire about/behavioral financial matters, George Ainslie focuses out[25] that fixation can be given a role as an intertemporal PD issue between the present and future selves of the junkie. For this situation, surrendering implies backsliding, and it is anything but difficult to see that not abandoning both today and later on is by a wide margin the best result. The situation where one goes without today, however, backslides, later on, is the most exceedingly terrible effect. In some sense, the train and benevolence required in going without today have been "squandered" because the future back slide implies that the someone who is addicted is ideal back where he began and should begin once again (which is very dampening and makes beginning once again more troublesome). Backsliding today and tomorrow is a somewhat "better" result, because while the someone who is addicted is still dependent, they haven't put the exertion into attempting to stop. The last case, where one participates in the addictive conduct today while going without "tomorrow" will be recognizable to any individual who has battled with a habit. The issue here is that (as in different PDs) there is an undeniable advantage to absconding "today," yet tomorrow one will confront a similar PD, and the same evident advantage will be available then, at last prompting to a perpetual series of surrenders. John Gottman in his exploration portrayed in "the study of trust" characterizes great connections as those where accomplices know not to enter the $(D, D)$ cell or if nothing else not to stall out there in a circle.

\subsection{In Economy}

Publicizing is some of the time referred to as a whole case of the detainee's difficulty. At the point when cigarette promoting was lawful in the United States, contending cigarette makers needed to choose how much cash to spend on publicizing. The adequacy of Firm A's promoting was somewhat dictated by the publicizing led by Firm B.
Similarly, the benefit got from promoting for Firm B is influenced by the publicizing led by Firm A. On the off chance that both Firm An and Firm B publicized amid a given period, then the promoting offsets, receipts stay consistent, and costs increment because of the cost of promoting. Both firms would profit by a lessening in publicizing. In any case, ought to Firm B pick not to promote, Firm A could profit incredibly by publicizing. By and by, the ideal measure of promoting by one firm relies on upon how much publicizing alternate attempts. As the best technique is reliant on what the other firm picks there is no overwhelming system, which makes it marginally unique about a detainee's issue. The result is comparative, however, in that both firms would be in an ideal situation were they to publicize not exactly in harmony. Some of the time agreeable practices do rise in business circumstances. For example, cigarette producers embraced the making of laws banning cigarette promoting, understanding this would lessen expenses and increment benefits over the industry [12]. This examination is probably going to be correlated in numerous different business circumstances including advertising. Without enforceable understandings, individuals from a cartel are additionally required in a (multiplayer) detainee's dilemma.[13] "Coordinating" ordinarily implies keeping costs at a pre-concurred least level. "Absconding" implies offering under this base level, quickly taking business (and benefits) from other cartel individuals. Against trust powers need potential cartel individuals to desert commonly, guaranteeing the most reduced conceivable costs for purchasers.

\subsection{In Sport}

Doping in the game has been referred to for instance of a detainee's dilemma [14].Two contending competitors have the alternative to utilize an unlawful as well as unsafe medication to support their execution. On the off chance that neither one of the athletes takes the medication, then neither increases leeway. If just a single does, then that competitor picks up a huge favorable position over their rival, diminished by the lawful as well as therapeutic perils of having taken the medication. On the off chance that both competitors take the medication, nonetheless, the advantages offset and just the perils remain, putting them both in a more terrible position than if neither had utilized doping [14].

\subsection{Many Players' Dilemma}

Some genuine situations include different players [15].Although figurative, Hardin's catastrophe of the hall might be seen for instance of a multi-player speculation of the PD: Each villager settles on a decision for personal pick up or restriction. The aggregate reward for consistent (or even regular) abandonment is low settlements (speaking to the obliteration of the "center"). A lodge difficulty the vast majority can identify with is washing the dishes in a common house. By not washing dishes an individual can pick up by sparing his time, however, if that conduct is embraced by each occupant the aggregate cost is no clean plates for anybody.

The center is not misused: William Poundstone, in a book about the detainee's problem (see References beneath), portrays a circumstance in New Zealand where daily paper boxes are left opened. It is feasible for individuals to take a paper without paying (abandoning) yet not very many do, feeling that on the off chance that they don't pay then neither will others, pulverizing the framework. Resulting research by Elinor Ostrom, champ of the 2009 Sveriges Riksbank Prize in Economic Sciences in Memory of Alfred Nobel, theorized 
that the deplorability of the center is distorted, with the negative result affected by external impacts. Without entangling weights, benches convey and deal with the hall among themselves for their shared advantage, authorizing social standards to safeguard the asset and accomplish the most extreme useful for the gathering, a case of affecting the best case result for PD [16].

\section{CONCLUSION}

This paper explained how PD works to understand it. Many strategies are intensively discussed academically, and real examples are given with a brief explanation. The Prisoner's Dilemma is a great game the theory between two players or more and each wants to get the higher score. The prisoner's dilemma is a type of non-zero sum game. Non-zero sum game means the total score distributed among the players depends on the action chosen. There are many strategies for the Prisoner's Dilemma (PD) we can choose. What is the best depends on what other player is likely to be doing?

\section{ACKNOWLEDGMENT}

The author would like to thank Saudi Arabian Cultural Mission (SACM) for the financially support through Al- Baha University. I also would like to thank my supervisor, Larry Wang, for his comments.

\section{REFERENCES}

[1] Milovsky, Nicholas. The Basics of Game Theory and Associated Games. Retrieved 11 February 2014.

[2] Fehr, Ernst; Fischbacher, Urs (Oct 23, 2003). The Nature of human altruism. Nature Publishing Group. 425(6960): 785-791

[3] Tversky, Amos; Shafir, Eldar (2004). Preference, Belief, and Similarity: Selected writings. Massachusetts Institute of Technology Press. ISBN 9780262700931. Retrieved February 27, 2013.

[4] Toh-Kyeong, Ahn; Ostrom, Elinor; Walker, James (Sep 5, 2002). Incorporating Motivational Heterogeneity into Game-Theoretic Models of Collective Action. Public Choice. 117 (3-4). Retrieved June 27, 2015.
[5] Oosterbeek, Hessel; Sloof, Randolph; Van de Kuilen, Gus (Dec 3, 2003). Cultural Differences in Ultimatum Game Experiments: Evidence from a MetaAnalysis. Experimental Economics. Springer Science and Business Media B.V. 7 (2): 171-188. doi:10.1023/B: EXEC.0000026978.14316.74. Retrieved February 27, 2013.

[6] Capraro, V (2013). A Model of Human Cooperation in Social Dilemmas. PLoS ONE. 8 (8): e72427. doi:10.1371/journal.pone.0072427.

[7] Kaznatcheev, Artem (March 2, 2015). A short history of iterated prisoner's dilemma tournaments. Theory, Evolution, and Games Group. Retrieved February 8, 2016.

[8] Markets \& Data. The Economist. 2007-09-27.

[9] Rehmeyer, Julie (2012-10-29). Game theory suggests current climate negotiations won't avert catastrophe". Science News. Society for Science \& the Public.

[10] Osang and Nandy 2003.

[11] Dawkins, Richard (1976). The Selfish Gene. Oxford University Press.

[12] Ainslie, George (2001). Breakdown of Will. ISBN 0521-59694-7.

[13] Nicholson, Walter (2000). Intermediate Microeconomics" (8th ed.). Harcourt.

[14] Schneier, Bruce (2012-10-26). "Lance Armstrong and the Prisoners' Dilemma of Doping in Professional Sports | Wired Opinion". Wired.com. Retrieved 2012-10-29.

[15] Gokhale CS, Traulsen A. Evolutionary games in the multiverse. Proceedings of the National Academy of Sciences. 2010 Mar 23;107(12):5500.

[16] The Volokh Conspiracy " Elinor Ostrom and the Tragedy of the Commons." Volokh.com. 2009-10-12. Retrieved 2011-12-17. 